Supporting Information for

\title{
How Do Proteins Associate with Nanoscale Metal-Organic Framework Surfaces?
}

Jacob G. Turner and Catherine J. Murphy

Department of Chemistry, University of Illinois at Urbana-Champaign, 600 S. Mathews Avenue, Urbana, Illinois 61801, United States

\section{SUPPLEMENTARY FIGURES}

Figure S1. TEM images of CTAB AuNRs

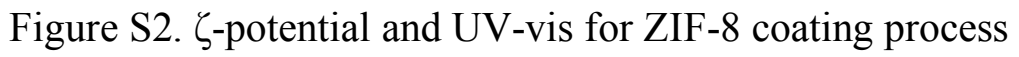

Figure S3. TEM images and UV-vis of citrate AuNSs

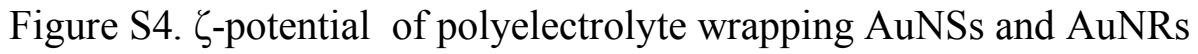

Figure S5. DLS sizing of nanoZIF-8

Figure S6. BET surface area analysis for nanoZIF-8

Figure S7. Pore size distribution for nanoZIF-8

Figure S8. BET surface area analysis for AuNR@ZIF-8

Figure S9. Pore size distribution for AuNR@ZIF-8

Figure S10. Powder XRD of nanoZIF-8 after incubation in $0.1 \mathrm{mM} \mathrm{NH}_{4} \mathrm{HCO}_{3}$

Figure S11. UV-vis of AuNR@ZIF-8 after protein incubation

Figure S12. ל-potential for AuNR@ZIF-8 after protein incubation 


\section{SUPPLEMENTARY EQUATIONS}

Equation S1. Determining mass of AuNR@ZIF-8 9

Equation S2. Determining total surface in solution $\quad 9$

Equation S3. Amount of protein adsorbed $\quad 9$

Equation S4. Normalizing protein adsorption $\quad 9$

3. REFERENCES 10 


\section{SUPPLEMENTARY FIGURES}

A)

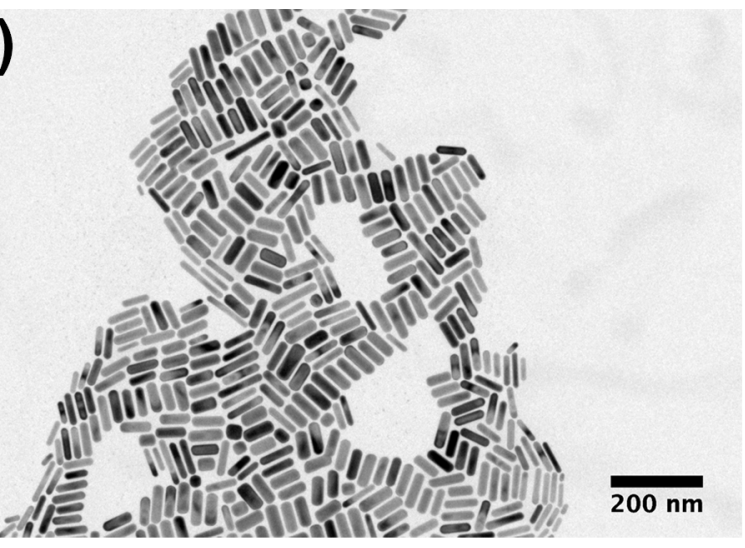

B)

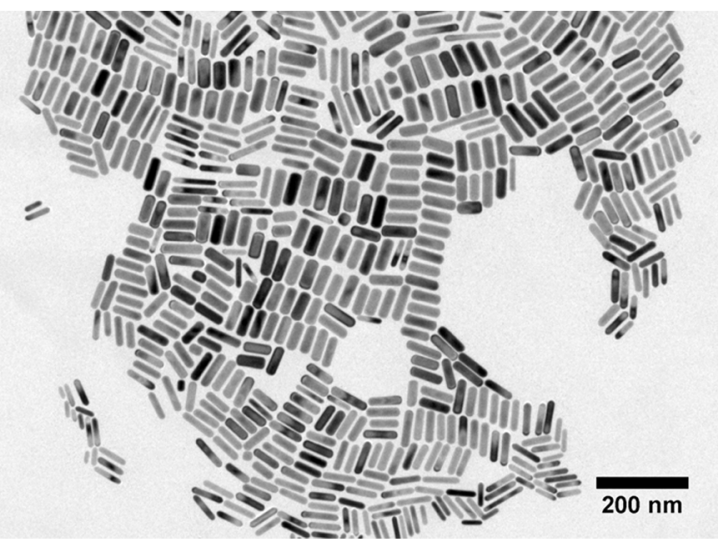

C)

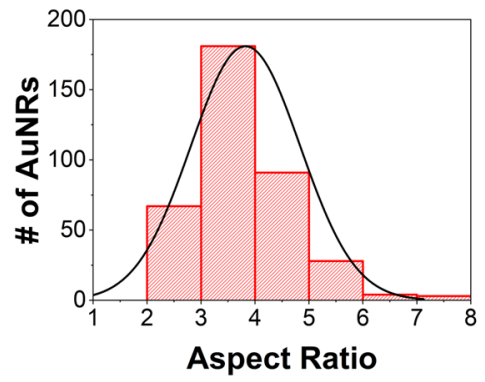

D)

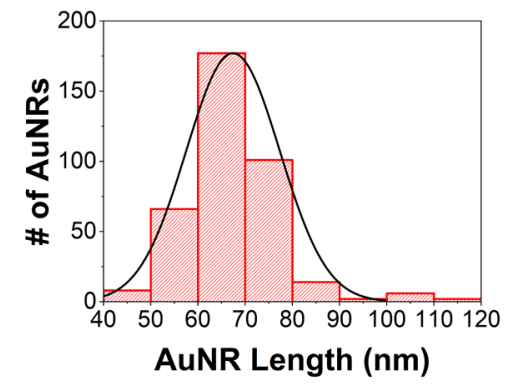

E)

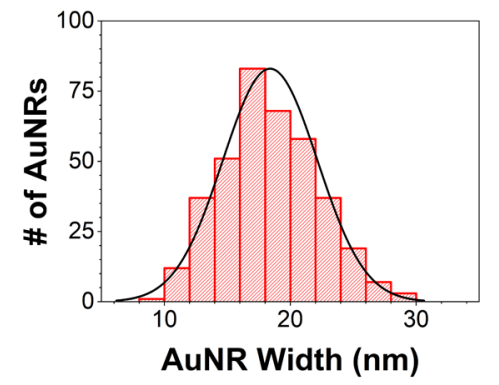

Figure S1: Representative TEM images of as synthesized CTAB AuNRs are shown in (A) and (B). TEM sizing analysis for CTAB AuNRs (C) Aspect ratio distribution (D) Length distribution (E) Width distribution.

A)

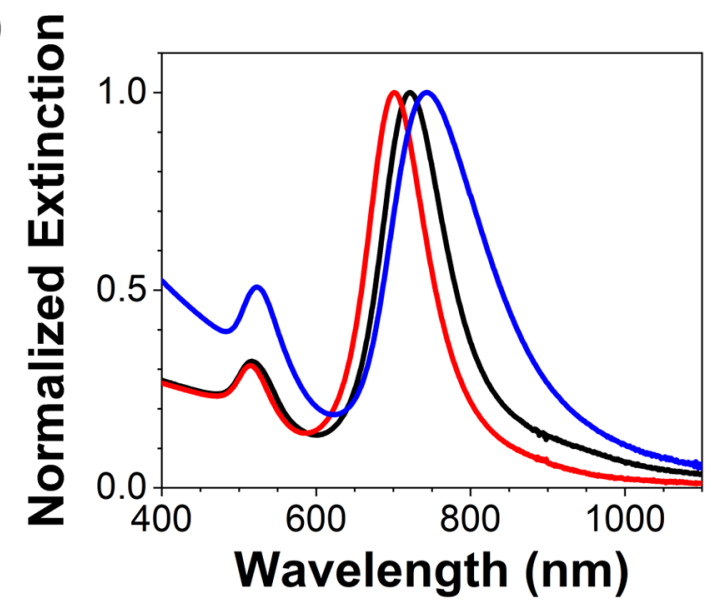

B)

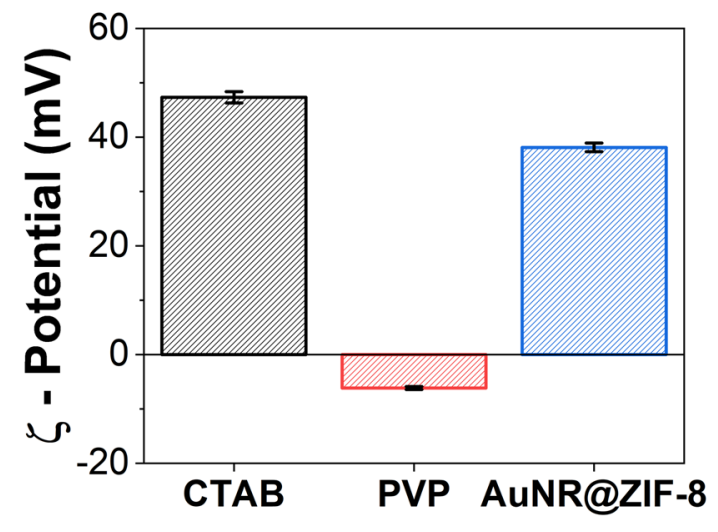

Figure S2: Characterization data for the AuNR functionalization process. (A)UV-vis extinction spectra (Black-CTAB, Red-PVP, Blue-ZIF-8). (B) $\zeta$ - potential measurements of each solution (CTAB AuNRs were dispersed in nanopure water, PVP and AuNR@ZIF-8 nanorods were dispersed in methanol). 
A)

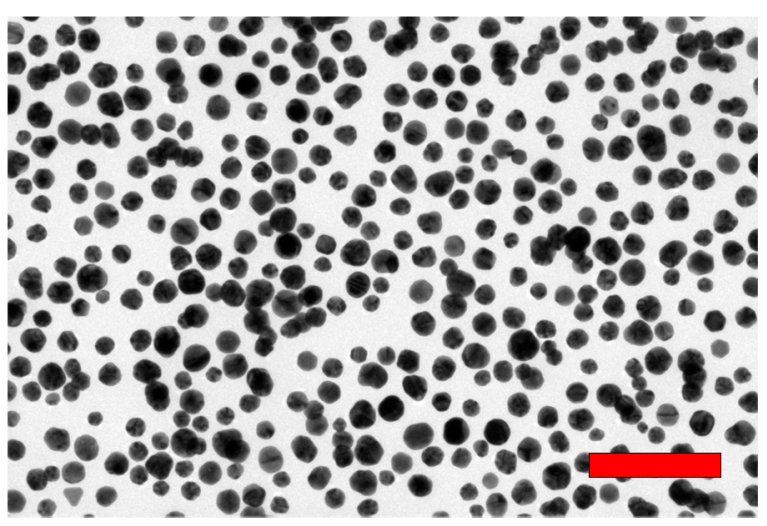

B)

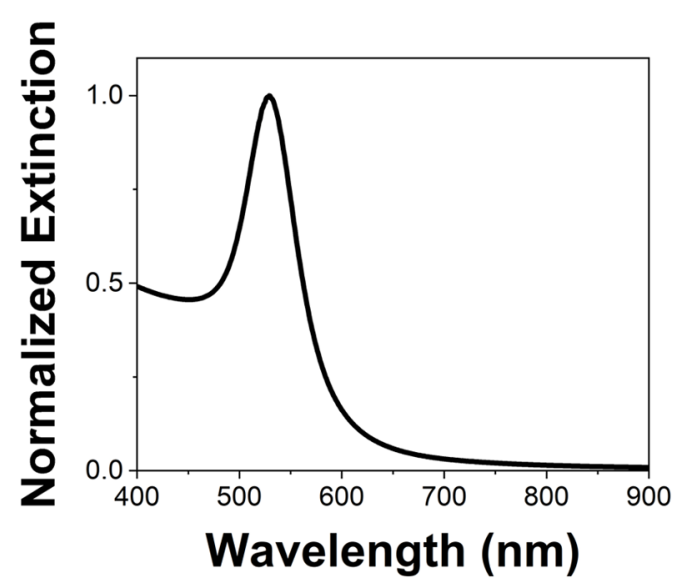

C)

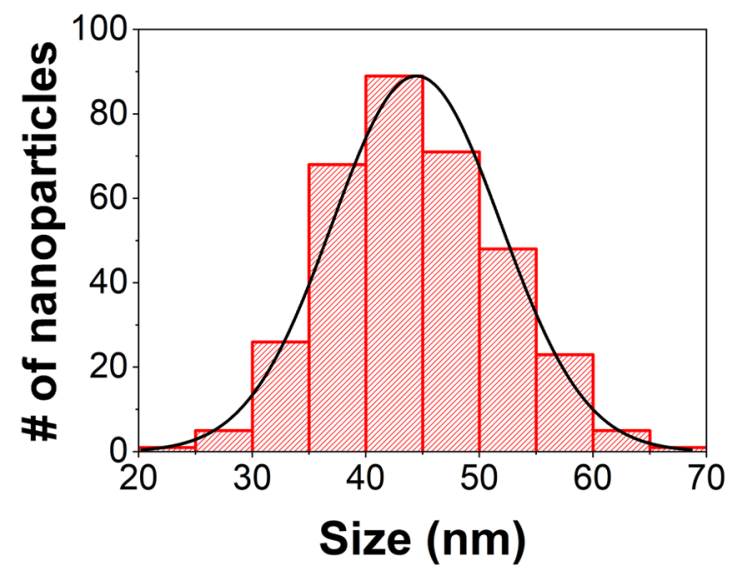

Figure S3: Characterization of citrate capped AuNS ( $44 \pm 8 \mathrm{~nm})$. (A) Representative TEM image (scale bar $=300 \mathrm{~nm})(\mathrm{B}) \mathrm{UV}$-vis extinction spectrum (C) Size distribution measured by TEM.

A)

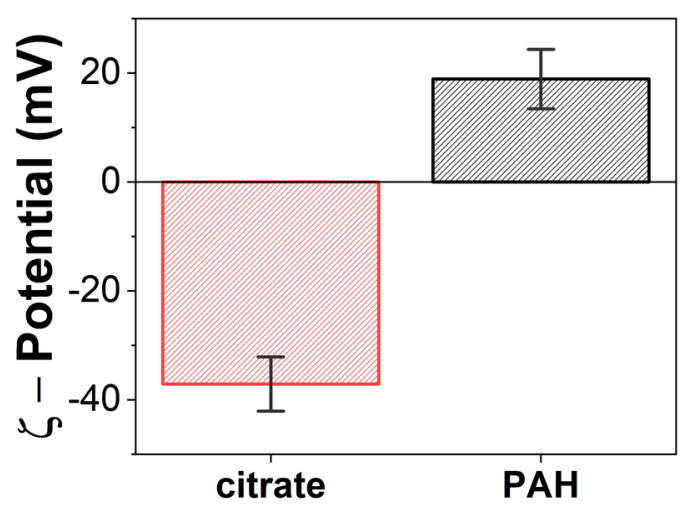

B)

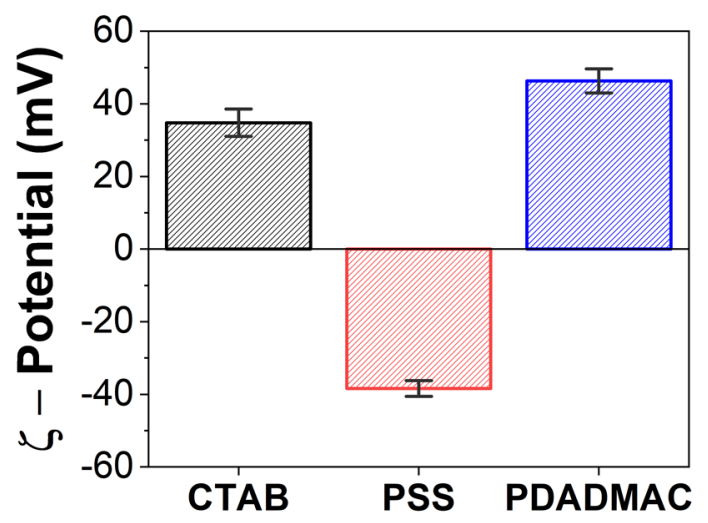

Figure S4: $\zeta$-potential of polyelectrolyte wrapping of (A) AuNSs and (B) AuNRs. The terminal polyelectrolyte layer (PAH or PDADMAC) provides a similar positive surface charge to that of the ZIF-8. 


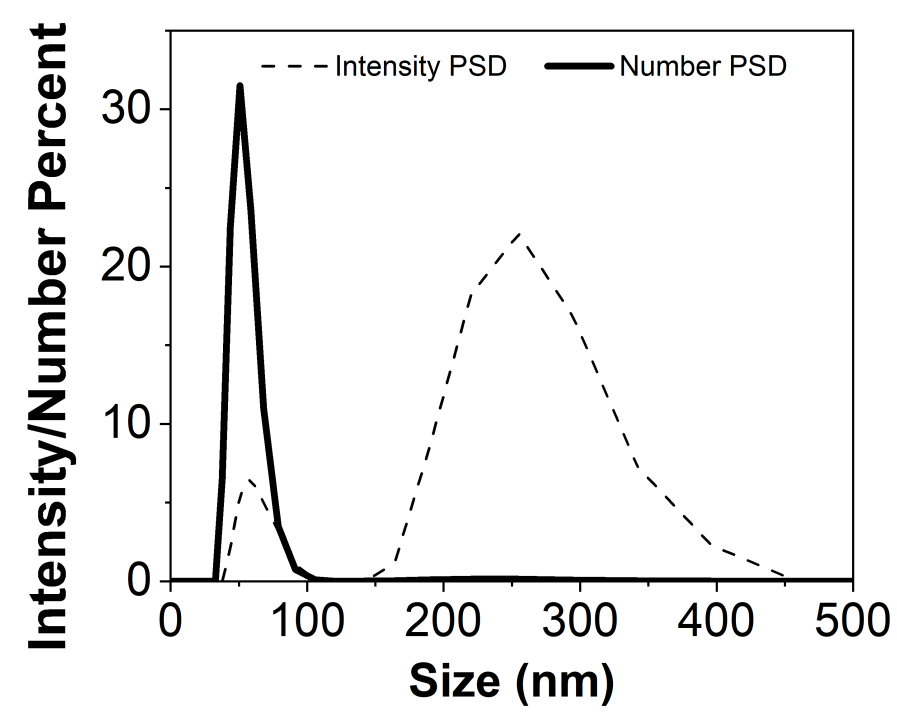

Figure S5: Dynamic Light Scattering (DLS) sizing data of nanoZIF-8 particle in EtOH. Using the number particle size distribution, the size was $49 \pm 4 \mathrm{~nm}$. The intensity distribution is skewed due to the few large ZIF-8 particles produced during the synthesis.

A)

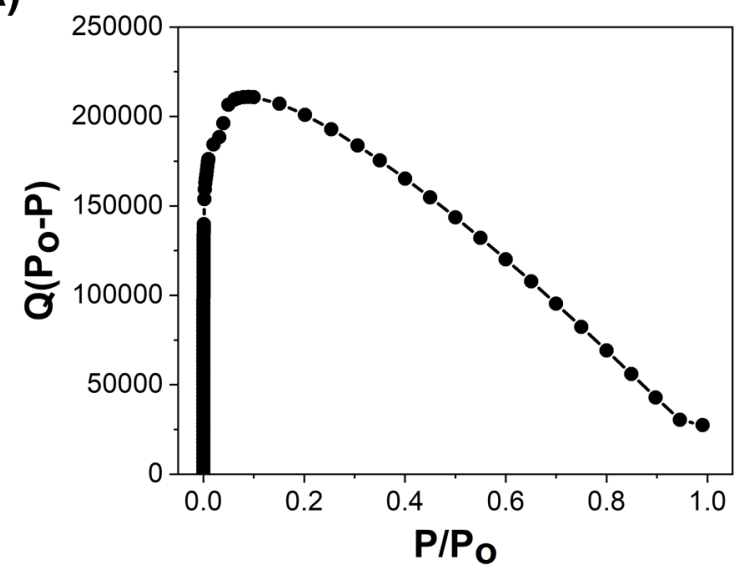

B)

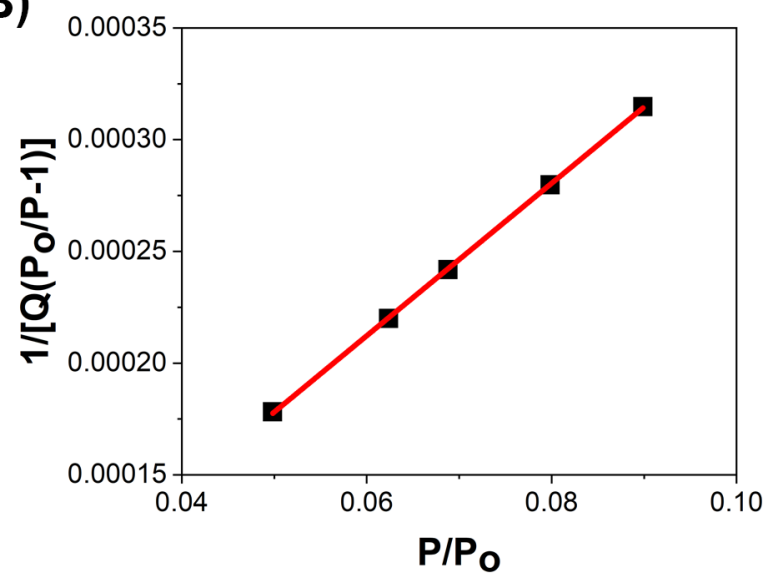

Figure S6: BET surface area analysis for nanoZIF-8. (A) Plot to determine the relative pressure area that the BET equation can be appropriately applied. The BET equation should only be applied within a pressure range that is continually increasing. (B) Linear relationship where the BET equation was applied. BET surface area was $1274 \mathrm{~m}^{2} / \mathrm{g}$ and the c-constant was 453 . 


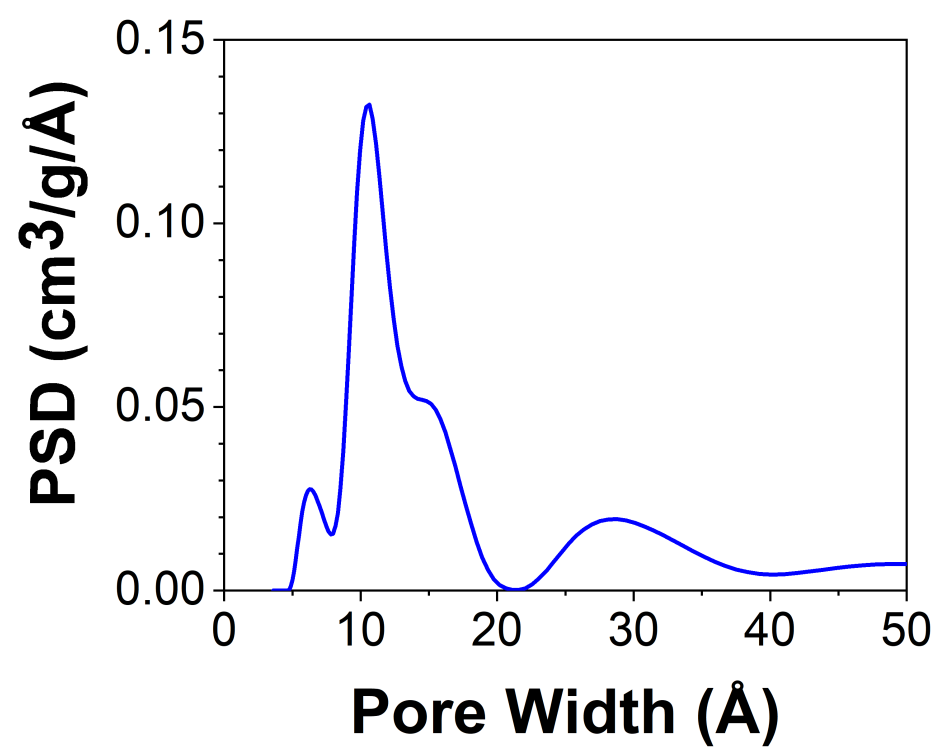

Figure S7: NanoZIF-8 pore size distribution determined using non-local density functional theory (NLDFT) methods and the demo version of the SAIEUS software from micromeritics. ${ }^{1}$
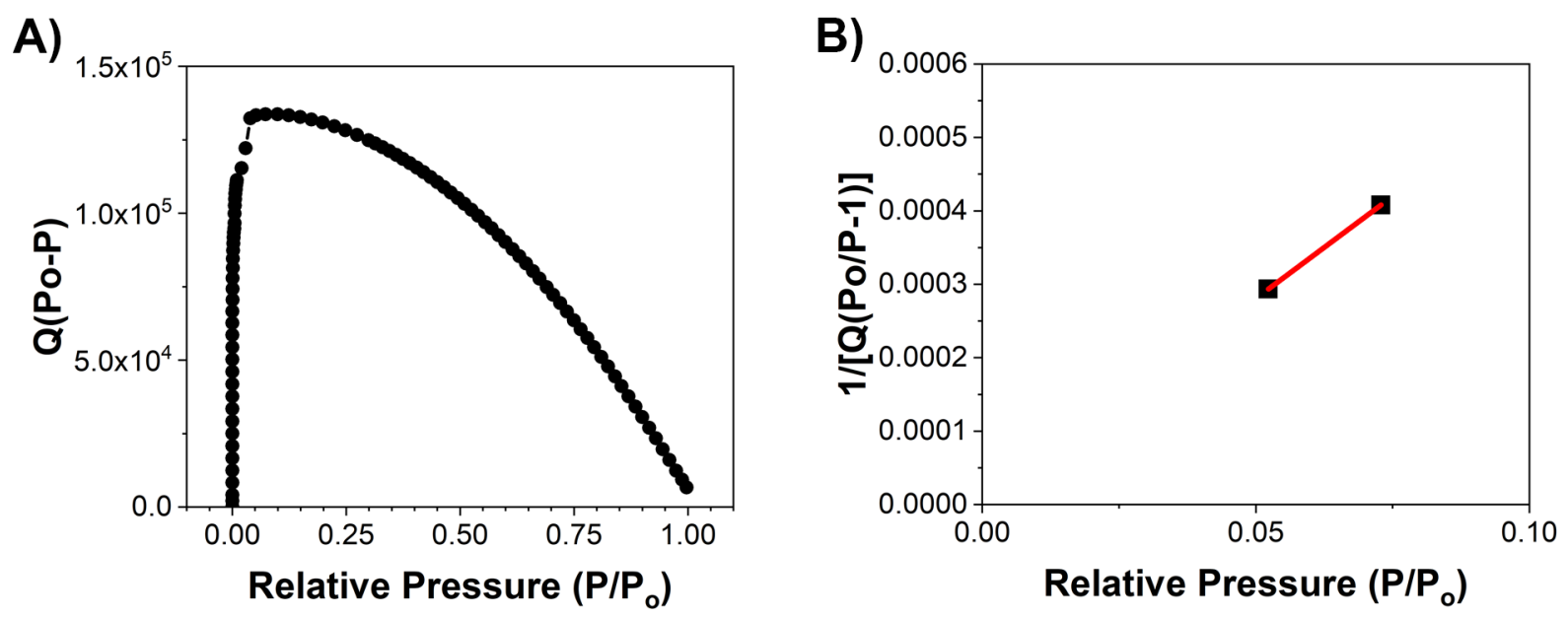

Figure S8: BET surface area analysis for AuNR@ZIF-8. (A) Plot to determine the relative pressure area that the BET equation can be appropriately applied. The BET equation should only be applied within a pressure range that is continually increasing. (B) Linear relationship where the BET equation was applied. BET surface area was $783 \mathrm{~m}^{2} / \mathrm{g}$ and the c-constant was 1987 . When determining the AuNR@ZIF-8 surface area from the MOF shell alone the BET surface area was $1264 \mathrm{~m}^{2} / \mathrm{g}^{2}$ 


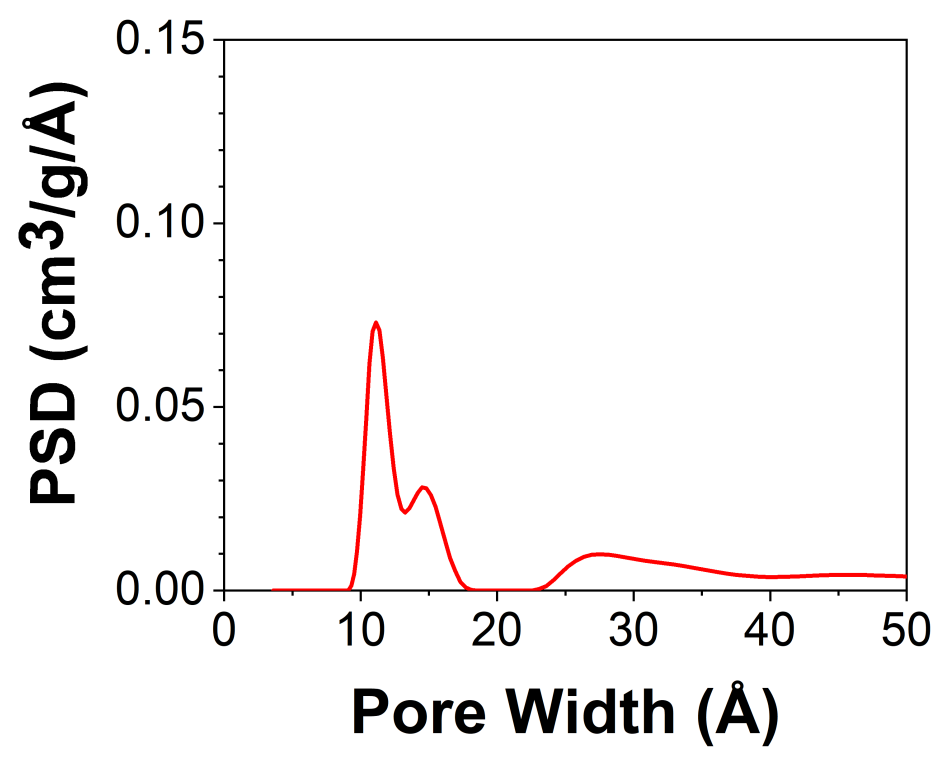

Figure S9:AuNR@ZIF-8 pore size distribution determined using non-local density functional theory (NLDFT) methods and the demo version of the SAIEUS software from micromeritics. ${ }^{1}$ (A) Zoomed in view of the microporous porous region. (B) Entire pore size distribution.

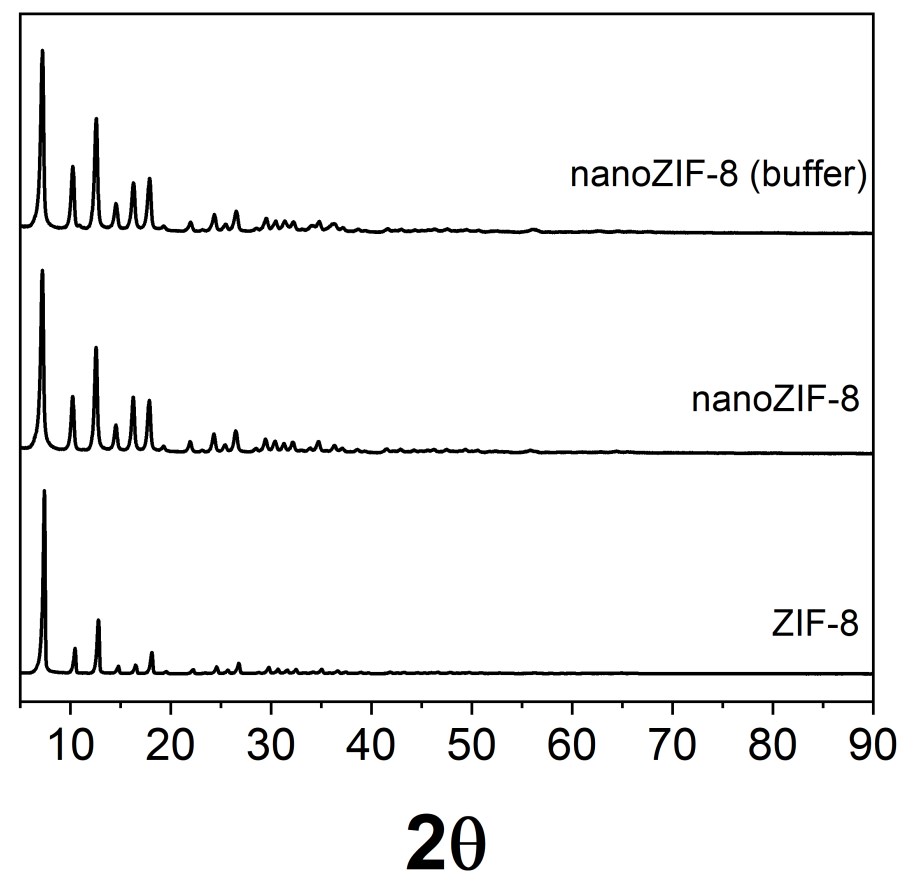

Figure S10: Powder XRD of nanoZIF-8 after sitting in $0.1 \mathrm{mM}$ ammonium bicarbonate for 24 hours. 

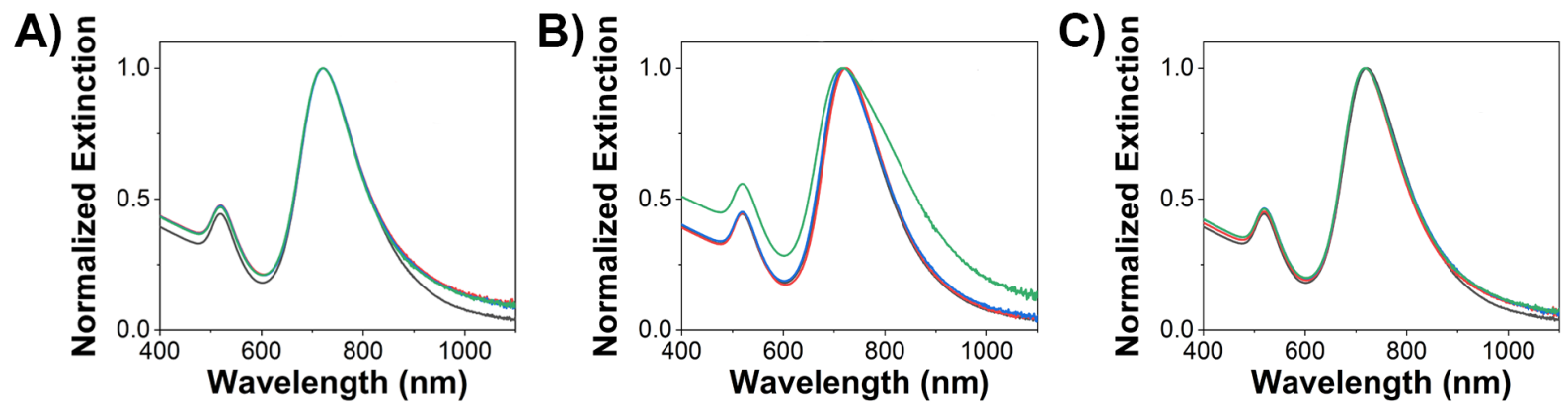

Figure S11: UV-vis of AuNR@ZIF-8 at varying time points after being incubated in a $1 \mathrm{mg} / \mathrm{mL}$ protein solutions in $0.1 \mathrm{mM}$ ammonium bicarbonate. (A) BLG-A (B) LYS (C) BSA. The minimal peak broadening shows that the AuNR@ZIF-8 particles are not aggregating in the presence of BLG-A. (Black - no protein, Red - 0 hrs, Blue - 2 hrs, Green - 24 hrs)

A)

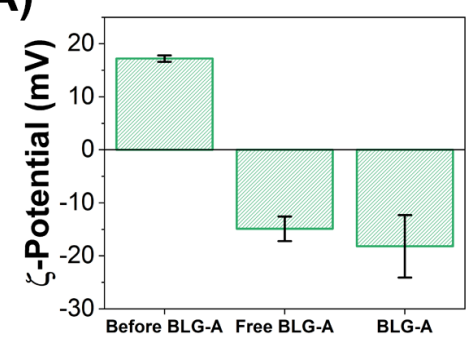

B)

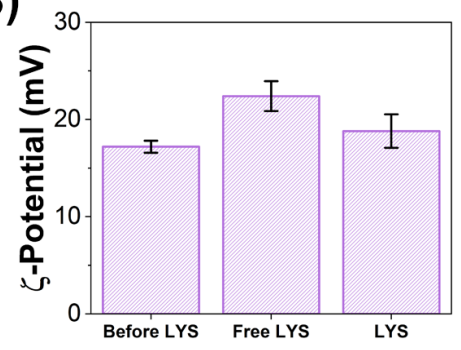

C)

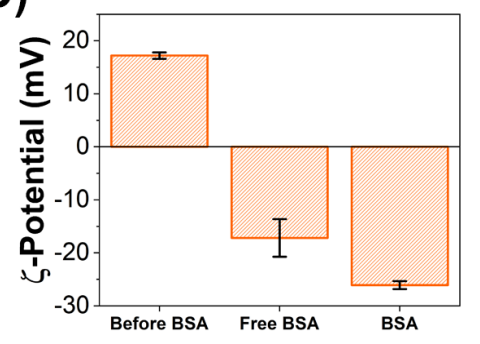

Figure S12: $\zeta$-potential of AuNR@ZIF-8 before and after protein incubation compared to the $\zeta$ potential of the free proteins. (A) BLG-A (B) LYS (C) BSA

A)

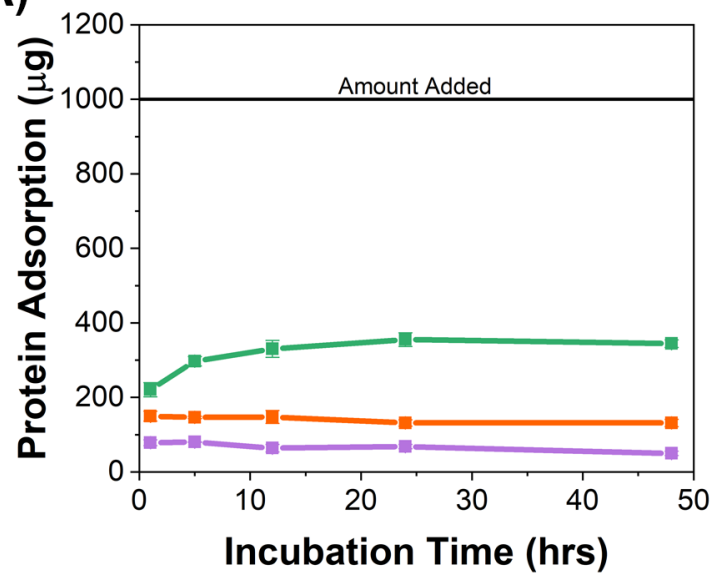

B)

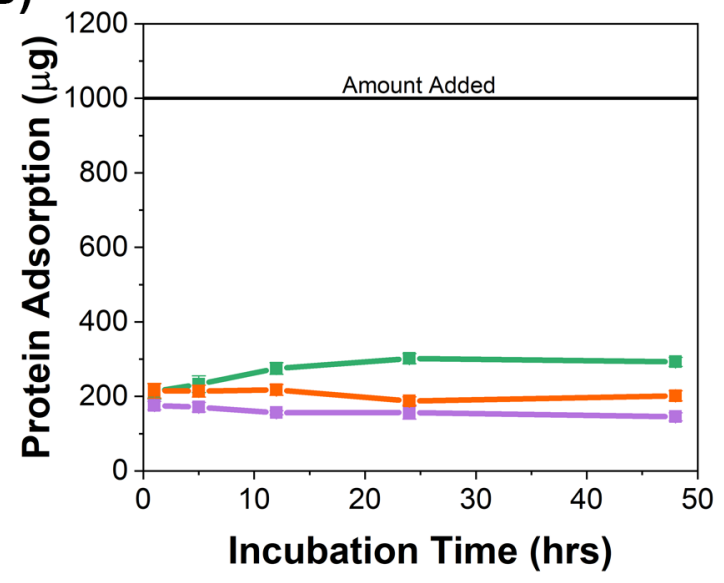

Figure S13: BCA assay results showing the amount of protein that was adsorbed to (A) nanoZIF8 and (B)AuNR@ZIF-8. $1 \mathrm{mg}$ of each protein was initially added. The total volume for each sample was $1 \mathrm{~mL}$; the nanoZIF-8 concentration was $0.5 \mathrm{mg} / \mathrm{mL}$ and the AuNR@ZIF-8 concentration was $0.5 \mathrm{nM}$. The amount of protein adsorbed was determined by determining the amount remaining in the supernatant and subtracting that from the total amount added. 


\section{SUPPLEMENTARY EQUATIONS}

Equation S1. Determining mass of AuNR@ZIF-8, where M = mass, V = volume, 1= length, w $=$ width, and $\rho=$ density.

$$
\begin{array}{cl}
M=V \times \rho & V=\pi\left(l w^{2}+\frac{4 w^{3}}{3}\right) \\
\mathrm{L}_{\text {AuNR }}=85 \mathrm{~nm} & \mathrm{~L}_{\mathrm{ZIF-}-8}=165 \mathrm{~nm} \\
\mathrm{~W}_{\text {AuNR }}=22 \mathrm{~nm} & \mathrm{~W}_{\text {AuNR }}=102 \mathrm{~nm} \\
\rho_{\text {AuNR }}=19.3 \mathrm{~g} / \mathrm{mL} & \rho_{\text {AuNR }}=0.35 \mathrm{~g} / \mathrm{mL}
\end{array}
$$

Equation S2. Determining total surface area in solution

$$
\text { BET S.A }\left(\frac{m^{2}}{g}\right) \times g \text { of nanoparticles in solution }=\text { Total Surface Area }\left(m^{2}\right)
$$

Equation S3. Amount of protein adsorbed

Total protein added $(\mu g)-$ Proteinin in supernatant $(\mu g)=$ Protein adsorbed $(\mu g)$

Equation S4. Normalizing protein adsorption

$$
\frac{\text { Protein adsorbed }(\mu g)}{\text { Total Surface Area }\left(m^{2}\right)}
$$




\section{REFERENCES}

(1) Kupgan, G.; Liyana-Arachchi, T. P.; Colina, C. M. NLDFT Pore Size Distribution in Amorphous Microporous Materials. Langmuir 2017, 33, 11138-11145.

(2) Hinman, J. G.; Turner, J. G.; Hofmann, D. M.; Murphy, C. J. Layer-by-Layer Synthesis of Conformal Metal-Organic Framework Shells on Gold Nanorods. Chem. Mater. 2018, 30, 72557261. 